\title{
Modelling the metal atom positions of the Photosystem II water oxidising complex: a density functional theory appraisal of the $1.9 \AA$ A resolution crystal structure $\dagger$
}

\author{
Simon Petrie, Phillip Gatt, Rob Stranger* and Ron J. Pace \\ Received 30th March 2012, Accepted 21st June 2012 \\ DOI: $10.1039 / \mathrm{c} 2 \mathrm{cp} 41020 \mathrm{f}$
}

\begin{abstract}
Density functional theory (DFT) calculations are reported for a set of model compounds intended to represent the structure of the Photosystem II (PSII) water oxidising complex (WOC) as determined by the recent $1.9 \AA$ resolution single crystal X-ray diffraction (XRD) study of Umena et al. In contrast with several other theoretical studies addressing this structure, we find that it is not necessary to invoke photoreduction of the crystalline sample below the $\mathrm{S}_{1}$ 'resting state' in order to rationalise the observed WOC geometry. Our results are consistent with crystallised PSII in the $\mathrm{S}_{1}$ state, with $\mathrm{S}_{1}$ corresponding to either $\left(\mathrm{Mn}^{\mathrm{III}}\right)_{4}$ or $\left(\mathrm{Mn}^{\mathrm{III}}\right)_{2}\left(\mathrm{Mn}^{\mathrm{IV}}\right)_{2}$ as required by the two competing paradigms for the WOC oxidation state pattern. Of these two paradigms, the 'low-oxidation-state' paradigm provides a better match for the crystal structure, with the comparatively long $\mathrm{Mn}(2)-\mathrm{Mn}(3)$ distance in particular proving difficult to reconcile with the 'high-oxidation-state' model. Best agreement with the set of metal-metal distances is obtained with a $\mathrm{S}_{1}$ model featuring $\mu-\mathrm{O}, \mu-\mathrm{OH}$ bridging between $\mathrm{Mn}(3)$ and $\mathrm{Mn}(4)$ and deprotonation of one water ligand on $\mathrm{Mn}(4)$. Theoretical modelling of the $1.9 \AA$ structure is an important step in assessing the validity of this recent crystal structure, with implications for our understanding of the mechanism of water oxidation by PSII.
\end{abstract}

\section{Introduction}

$\mathrm{X}$-ray crystallography has proven a powerful instrument in the quest to characterise many biomolecules, but has been 'challenged' in its application to Photosystem II (PSII), whose water oxidising complex (WOC) is known to feature four $\mathrm{Mn}$ atoms and one $\mathrm{Ca}$ atom. While several XRD structures for PSII have now been reported, ${ }^{1-7}$ at progressively improved resolution, they differ in some important respects in their depiction of the WOC. Chief of these 'bones of contention' has been the distance between $\operatorname{Mn}(1)$ and $\operatorname{Mn}(4)$, which has values of $3.25 \AA$ in the $(3.5 \AA$ resolution) study of Ferreira et al. ${ }^{4} 4.96 \AA$ in the $(3.7 \AA$ resolution) study of Kamiya and Shen, ${ }^{2}$ and $5.43 \AA$ in the (3.0 $⿱$ resolution) study of Loll et al. ${ }^{5}$ (A comparison of the WOC metal-atom architechures obtained through these XRD studies is given in Fig. 1.) The variability in the $\mathrm{Mn}(1)-\mathrm{Mn}(4)$ distance contrasts with consistency in other aspects of the reported geometries, which have been satisfactorily interpreted by a structure in which $\mathrm{Mn}(1), \operatorname{Mn}(2), \operatorname{Mn}(3)$ and $\mathrm{Ca}$ form the four metal-atom

Research School of Chemistry, College of Science,

Australian National University, Canberra ACT 0200, Australia.

E-mail:Rob.Stranger@anu.edu.au

$\dagger$ Electronic supplementary information (ESI) available. See DOI: $10.1039 / \mathrm{c} 2 \mathrm{cp} 41020 \mathrm{f}$ vertices of a rigidly O-bridged cubanoid unit to which $\mathrm{Mn}(4)$ is connected by a more flexible bridging arrangement to $\mathrm{Mn}(3)$. (For this reason, $\mathrm{Mn}(4)$ is often referred to as the 'dangler' ion within the WOC.) This disparity between different crystal structures might reflect variations introduced by differences in the chemical workup leading to crystallisation. ${ }^{8,9}$ In this regard we note that the variation in crystallographic metal positions can be accounted for by interconversion between approximately equi-energetic WOC isomers.We have shown that isomeric $\mathrm{Mn}_{4} \mathrm{Ca}$ complexes, modelled on the metal atom positions of the $3.7 \AA$. $3.5 \AA$, and $3.0 \AA$ resolution XRD structures and using the $3.0 \AA$ XRD study's protein ligation pattern, differ little in total energy at any given overall oxidation state. Further, some overall oxidation states appear to have notably low barriers to this structural interconversion. Alternatively, the different geometries have been postulated to arise from radiation damage due to the large X-ray fluxes required of XRD. ${ }^{10}$

Many other approaches have also been applied to characterising the WOC's structure. Relevant to the present work, several groups have used density functional theory (DFT) calculations on various models of the WOC. ${ }^{11}$ Batista and co-workers, ${ }^{12-19}$ Siegbahn and co-workers, ${ }^{20-31}$ Kusunoki, ${ }^{32,33}$ Ames and co-workers, ${ }^{33}$ and Yamanaka and co-workers ${ }^{35-37}$ have all performed calculations on a 'high-oxidation-state' (HOS) $\mathrm{CaMn}_{4}$ cluster in which the $\mathrm{S}_{1}$ state of PSII features an oxidation state pattern of $\left(\mathrm{Mn}^{\mathrm{III}}\right)_{2}\left(\mathrm{Mn}^{\mathrm{IV}}\right)_{2}$. 

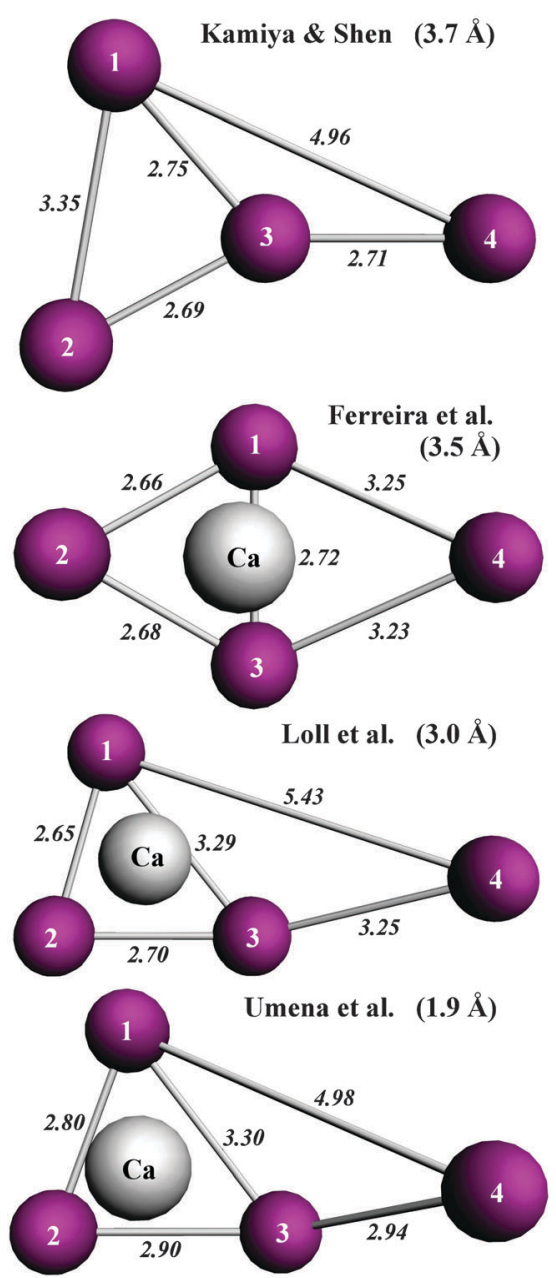

Fig. 1 Comparison of the WOC's metal atom positions obtained in the four most recent XRD studies ${ }^{2,4,5,7}$ of PSII.

In contrast, our own calculations ${ }^{8,9,38-40}$ have focussed on a 'low-oxidation-state' (LOS) paradigm where the $\mathrm{Mn}_{4}$ moiety of the $\mathrm{S}_{1}$ state has a mean $\mathrm{Mn}$ oxidation level of $3.0\left(\left(\mathrm{Mn}^{\mathrm{III}}\right)_{4}\right.$ or $\left.\left.\mathrm{Mn}^{\mathrm{IV}}\left(\mathrm{Mn}^{\mathrm{III}}\right)_{2} \mathrm{Mn}^{\mathrm{II}}\right)\right)$. Our preference for a LOS model over HOS derives in part from time-dependent DFT (TD-DFT) calculations of the Mn X-ray Absorption Near-Edge Structure (XANES) energies for a sequence of modelled WOC S states. ${ }^{41,42}$ When these are calibrated against the calculated XANES energies for a large, well-characterised set of Mn complexes (monomers and dimers) of known oxidation state, ${ }^{43,44}$ they yield a result consistent with the LOS paradigm. However, this choice of oxidation state paradigm remains contentious. Regardless of the oxidation state assignment, all but the most recent of the reported DFT optimisations ${ }^{19,31,33,35-37,40}$ have concerned models based upon either the $3.5 \AA$ resolution ${ }^{4}$ or the 3.0/2.9 $\AA$ resolution ${ }^{5,6}$ XRD structure.

The recent release of the XRD study, by Umena et al., ${ }^{7}$ with a resolution of $1.9 \AA$, presents yet another perspective in the tale of PSII structural determination. (A portion of this XRD structure is shown in Fig. 2.) Here the point of divergence is not so much the $\mathrm{Mn}(1)-\mathrm{Mn}(4)$ distance, which at $4.97 \AA$ is not dramatically at odds with the previous highest-resolution value of $5.43 \AA$ for this highly-variable parameter, but the triad of 'short' $\mathbf{M n}-\mathbf{M n}$ distances $\operatorname{Mn}(1)-\operatorname{Mn}(2), \operatorname{Mn}(2)-\operatorname{Mn}(3)$, and
$\mathrm{Mn}(3)-\mathrm{Mn}(4)$. Within the $1.9 \AA$ resolution structure, the $\operatorname{Mn}(1)-\operatorname{Mn}(2)$ and $\operatorname{Mn}(2)-\operatorname{Mn}(3)$ distances are, at $2.80 \AA$ and $2.90 \AA$, markedly elongated when compared to the corresponding values in the $3.5 \AA$ resolution structure of Ferreira et $a l .{ }^{4}$ and the 3.0/2.9 $\AA$ resolution structures of Loll et al., ${ }^{5,6}$ both of which reported values between $2.65 \AA$ and $2.70 \AA$ for these $\mathrm{Mn}-\mathrm{Mn}$ vectors. Additionally, since the $\mathrm{Mn}(1)-\mathrm{Mn}(2)$ and $\operatorname{Mn}(2)-\operatorname{Mn}(3)$ distances are widely considered to be responsible for the 'short' $\mathrm{Mn}-\mathrm{Mn}$ vectors at $\sim 2.7 \AA$ reported by EXAFS, ${ }^{45,46}$ the values reported for these distances in the new XRD structure would seem to be inconsistent with the EXAFS characterization of $\mathrm{Mn}-\mathrm{Mn}$ bondlengths. For $\mathrm{Mn}(3)-\mathrm{Mn}(4)$ the 'problem' is reversed: the latest XRD reports a shorter distance of $2.90 \AA$, which contrasts with the values of $3.23 \AA$ and $3.25 \AA$ returned by the studies of Ferreira et al. ${ }^{4}$ and Loll et al. ${ }^{5} \mathrm{~A}$ metal-metal distance of $3.5 \AA$ or less generally denotes a bridging interaction between the two metals, with a contraction from $3.2 \AA$ to $2.9 \AA$ implying a change in the mode of metal-metal bridging. Our existing models of the PSII WOC, featuring a carboxylate bridge (representing Glu333) and a single $\mu-\mathrm{O}$ (or, in some structural variants, $\mu-\mathrm{OH})$ bridge spanning $\mathrm{Mn}(3)$ and $\operatorname{Mn}(4),{ }^{8,9,38-40}$ return $\mathrm{Mn}(3)-\mathrm{Mn}(4)$ distance values which are broadly in keeping with those from the earlier XRD studies but are markedly at variance with the results from the $1.9 \AA$ crystal structure.

A further distinguishing feature of the new $1.9 \AA$ crystal structure $^{7}$ is that, for the first time, the bridging atoms (presumably $\mathrm{O}$ ) between the manganese have been formally located. (The $3.5 \AA$ structure of Ferreira et al. ${ }^{4}$ featured interpolated $\mathrm{O}$-atom bridges, but these were not so much detected as inferred on structural grounds.) The location of two (O)-bridges between $\mathrm{Mn}(3)$ and $\mathrm{Mn}(4)$ provides a plausible explanation for the $\mathrm{Mn}(3)-\mathrm{Mn}(4)$ contraction, but provokes many additional questions, several of which are currently best addressed through the medium of DFT calculations: how does the rest of the WOC structure respond to this previouslyunidentified $\mathrm{Mn}(3) / \mathrm{Mn}(4)$ bridging interaction? In what manner is the moiety identified in the new crystal structure as $\mathrm{O}(5)$, which may in principle be an $\mathrm{O}$ atom, a hydroxide ligand, or a water ligand, coordinated to the four metal atoms $(\mathrm{Mn}(1), \operatorname{Mn}(3)$, $\mathrm{Mn}(4)$, and Ca) from which it is between $2.4 \AA$ and $2.8 \AA$ distant? What is the Mn oxidation state pattern resulting from this connectivity, and does it differ from that found in previous computational studies of WOC models based on the earlier XRD structures? Can the $1.9 \AA$ crystal structure be modelled in a satisfactory manner through DFT calculations?

With regard to the latter question, a recent DFT study by Luber et al. ${ }^{19}$ has concluded that the $1.9 \AA$ XRD results may be contaminated by 'pre- $\mathrm{S}_{0}$-state intermediates such as $\mathrm{S}_{-1}$ and $\mathrm{S}_{-2}^{\prime}-\mathrm{a}$ view shared by Siegbahn ${ }^{31}$ and by Ames et al. ${ }^{34}$ and are therefore not truly representative of any of the five $\mathrm{S}$ states $\left(S_{0}\right.$ to $\left.S_{4}\right)$ involved in catalytic water oxidation. While this contention remains open to debate, it is unarguable that the $1.9 \AA$ crystal structure has delivered a wealth of structural detail on one of the most challenging metalloprotein structures currently under investigation, and for this reason it is important to discern the $\mathrm{Mn}$ oxidation state pattern and precise level of $\mathrm{O}$-atom protonation (the XRD's resolution is insufficient to assign $\mathrm{H}$ atoms, and therefore to distinguish, for example, between ligated $\mathrm{O}, \mathrm{OH}$, 


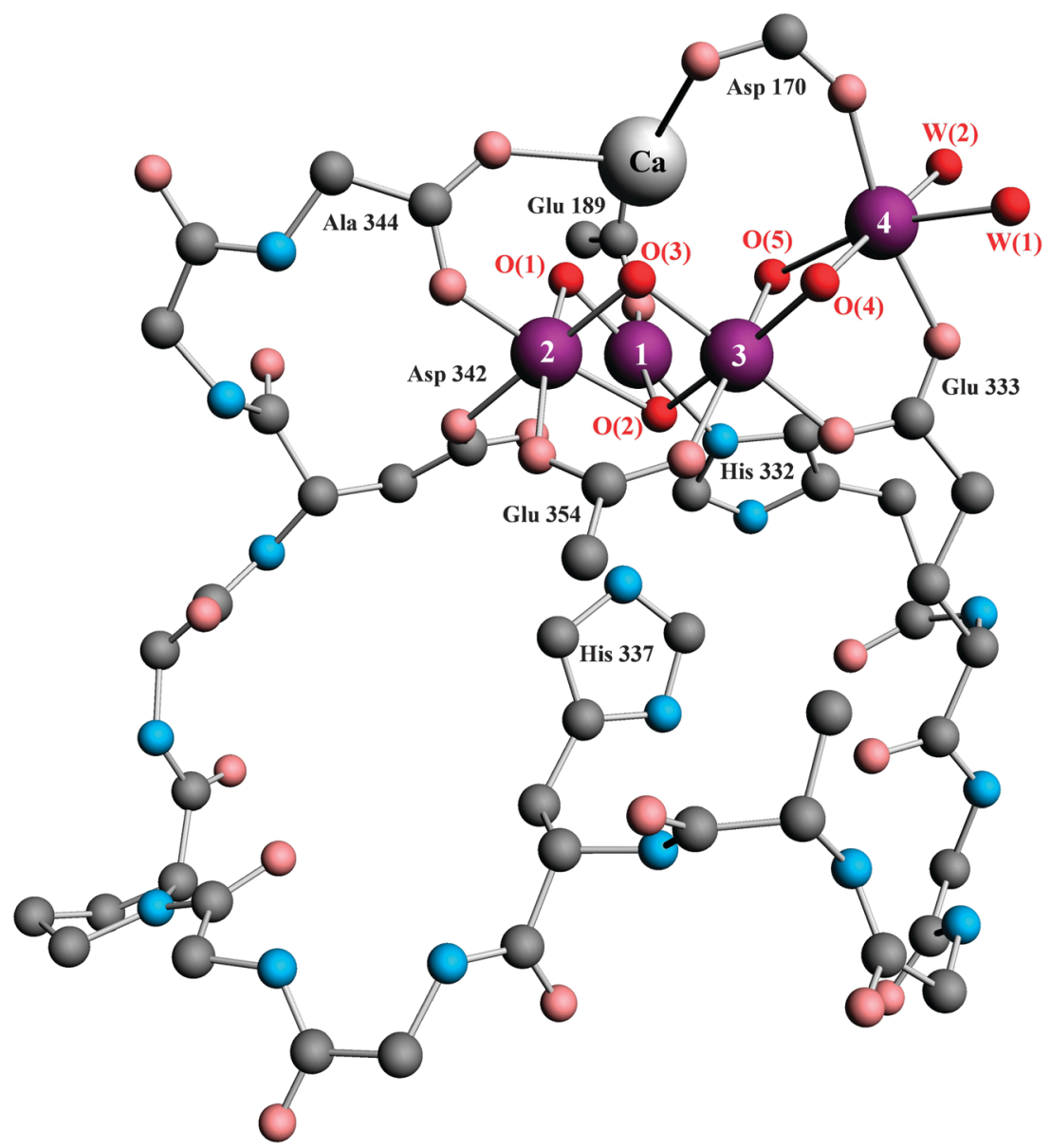

Fig. 2 Coordination environment of the WOC's $\mathrm{Mn}_{4} \mathrm{Ca}$ core, showing the ligating amino acid residues, the bridging $\mathrm{O}$ atoms $\mathrm{O}(1)-\mathrm{O}(5)$, and the two Mn(4)-ligated 'water' molecules W(1) and W(2), as revealed by the recent $1.9 \AA$ A resolution XRD study of Umena et al. ${ }^{7}$ For clarity, the bonds between $\mathrm{Ca}$ and $\mathrm{O}(1), \mathrm{O}(3)$ and $\mathrm{O}(5)$ are not shown.

or $\mathrm{OH}_{2}$ groups) for this structure. To this end, we present here results of a detailed study of DFT models for the latest $1.9 \AA$ XRD structure.

\section{Theoretical methods}

Density functional theory calculations employed the Amsterdam Density Functional (ADF) program, versions ADF 2009.01 and ADF 2010.01, developed by Baerends et al. ${ }^{47}$ Calculations were run in parallel mode on the VAYU supercomputer housed at the ANU Supercomputer Facility and operated under the National Computational Infrastructure facility.

Geometry optimizations, in $C_{1}$ symmetry, used the gradient algorithm of Versluis and Ziegler ${ }^{48}$ and featured convergence constraints twice as tight as the ADF default values. All calculations were performed in an unrestricted fashion, using all-electron basis sets.

Functionals used in the calculations were the local density approximation (LDA) to the exchange potential, the correlation potential of Vosko, Wilk and Nusair (VWN), ${ }^{49}$ and the nonlocal corrections of Becke ${ }^{50}$ and Perdew. ${ }^{51}$ When applied, dispersion effects were incorporated using the empirical formula of Grimme. ${ }^{52}$ The Slater type orbital basis sets used were of triple- $\zeta-$ plus-polarization quality (TZP) throughout for calculations on 'truncated' structures in which the amino acid residues (Ala344, Asp170, Asp342, Glu189, Glu333, Glu354, His332) directly coordinated to the $\mathrm{Mn}_{4} \mathrm{Ca}$ cluster were replaced with formate and imidazole groups. In calculations on 'extended' structures (i.e., those including three ligand connecting peptide 'straps' tethered to the $\mathrm{Mn}_{4} \mathrm{Ca}$ cluster), TZP basis sets were used for the $\mathrm{Mn}_{4} \mathrm{CaO}_{5}$ core, with all other atoms in the structure described by double- $\zeta$-plus-polarization quality (DZP) basis sets. Optimized geometries were initially obtained for the fully ferromagnetically coupled, all-high-spin state with $S_{\max }=8.5$ (' $\left.\mathrm{S}_{0}{ }^{\prime}\right), 8\left({ }^{\prime} \mathrm{S}_{1}{ }^{\prime}\right), 7.5\left({ }^{\prime} \mathrm{S}_{2}\right.$ '), or 7 (' $\left.\mathrm{S}_{3}{ }^{\prime}\right)$. Subsequent optimizations were pursued for the 'ABBA', 'ABAB', and 'AABB' antiferromagnetic coupling schemes, as we have described previously. $8,9,38-40$

\section{Results and discussion}

\section{Initial models}

Our first attempts to model the Umena et $a l^{7}$ XRD structure did so by the incorporation of an additional $\mu$-oxo bridge between $\mathrm{Mn}(3)$ and $\mathrm{Mn}(4)$ in a 'truncated' model analogous to those we have explored through previous studies, ${ }^{8,9,38-40}$ giving in this instance a structural template (1). Input structures adopted the same ligation pattern as had previously been used 
(i.e. consistent with the $2.9 \AA$ structure, with Glu189 bridging but not Asp170). It was generally found that our $1.9 \AA$ model structures spontaneously adopted a bridging mode for Asp170, while still retaining an effective bridging interaction for Glu189. Because it was not known whether the $\mathrm{Mn}(3) / \mathrm{Mn}(4)$ bridges were $\mathrm{O}$ atoms, $\mathrm{OH}$ ligands, or a combination of both, protonation of these bridging $\mathrm{O}$ atoms $\mathrm{O}(4)$ and $\mathrm{O}(5)$ was explored to canvass a greater range of structural options. Additionally, since the $\mathrm{Mn}(1)-\mathrm{Mn}(2)$ and $\mathrm{Mn}(2)-\mathrm{Mn}(3)$ bonds are markedly longer in the $1.9 \AA$ structure than is the case in the earlier XRD studies, the possibility of $\mu_{3}-\mathrm{O}$ protonation (at the $\mathrm{O}(2)$ position) was also explored. The consequences of protonation of the central $\mu_{3}-\mathrm{O}(2)$ oxo have been previously addressed in our recent study, ${ }^{40}$ though the focus in that work was not on modelling of the Umena et al. ${ }^{7}$ structure per se, but predominantly on the influence of $\mathrm{O}(2)$ protonation on the $\mathrm{Mn}(1)-\mathrm{Mn}(2)$ and $\mathrm{Mn}(2)-\mathrm{Mn}(3)$ distances.

Results from calculations on structure (1), for the various options of protonation at $\mathrm{O}(2), \mathrm{O}(4)$, and/or $\mathrm{O}(5)$, were assessed against the set of crystallographic metal-metal distances shown in Table 1.

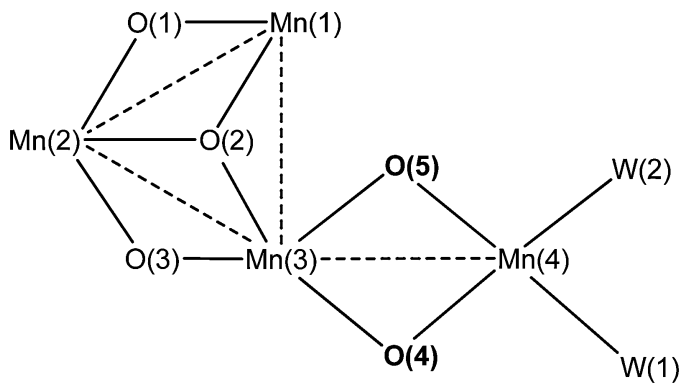

(1)

Comparison of the shortest $\mathrm{Mn}-\mathrm{Mn}$ distances (i.e., those bridged by one carboxylate and at least one $\mathrm{O}$ or $\mathrm{OH}$ ligand, viz. $\mathrm{Mn}(1)-\mathrm{Mn}(2), \mathrm{Mn}(2)-\mathrm{Mn}(3)$ and $\mathrm{Mn}(3)-\mathrm{Mn}(4))$ very strongly suggests that $\mathrm{O}(2)$ is not protonated: $\mathrm{O}(2)$ protonation yields theoretical structures across the range of modelled $S$ states $S_{0}$ to $\mathrm{S}_{3}$, and for both ferromagnetically- and antiferromagneticallycoupled configurations, in which $\mathrm{Mn}(1)-\mathrm{Mn}(2)$ and/or $\mathrm{Mn}(3)-$ $\mathrm{Mn}(4)$ are systematically too large by an increment of $0.15 \AA$ or greater. In contrast, several structural variants lacking $\mathrm{O}(2)$ protonation deliver acceptable values for these key $\mathrm{Mn}-\mathrm{Mn}$

Table 1 Metal-metal distances obtained from the various XRD structure determinations for the PSII WOC

\begin{tabular}{|c|c|c|c|c|}
\hline Parameter $/ \AA^{a}$ & $\begin{array}{l}\text { Kamiya/ } \\
\text { Shen }^{b}\end{array}$ & $\begin{array}{l}\text { Ferreira } \\
\text { et al. }{ }^{c}\end{array}$ & $\begin{array}{l}\text { Loll } \\
\text { et al. }{ }^{d}\end{array}$ & $\begin{array}{l}\text { Umena } \\
\text { et al. }\end{array}$ \\
\hline Resolution/Å & 3.7 & 3.5 & 3.0 & 1.9 \\
\hline$r[\mathrm{Mn}(1)-\mathrm{Mn}(2)]$ & 3.35 & 2.66 & 2.65 & $2.76 / 2.84$ \\
\hline$r[\operatorname{Mn}(2)-\operatorname{Mn}(3)]$ & 2.69 & 2.68 & 2.70 & $2.91 / 2.89$ \\
\hline$r[\mathrm{Mn}(1)-\mathrm{Mn}(3)]$ & 2.75 & 2.72 & 3.29 & $3.30 / 3.29$ \\
\hline$r[\mathrm{Mn}(3)-\mathrm{Mn}(4)]$ & 2.71 & 3.23 & 3.25 & $2.91 / 2.97$ \\
\hline$r[\mathrm{Mn}(1)-\mathrm{Mn}(4)]$ & 4.96 & 3.25 & 5.43 & $4.96 / 5.00$ \\
\hline$r[\mathrm{Ca}-\mathrm{Mn}(1)]$ & & 3.39 & 3.38 & $3.46 / 3.51$ \\
\hline$r[\mathrm{Ca}-\mathrm{Mn}(2)]$ & & 3.34 & 3.22 & $3.29 / 3.36$ \\
\hline$r[\mathrm{Ca}-\mathrm{Mn}(3)]$ & & 3.37 & 3.29 & $3.44 / 3.41$ \\
\hline$r[\mathrm{Ca}-\mathrm{Mn}(4)]$ & & 3.95 & 4.63 & $3.80 / 3.79$ \\
\hline
\end{tabular}

Notes: ${ }^{a}$ Refer to Fig. 1 for Mn atom ordering. ${ }^{b}$ Ref. 2. ${ }^{c}$ Ref. 4.

${ }^{d}$ Ref. 5. ${ }^{e}$ Ref. 7 . distances, and for $\operatorname{Mn}(2)-\operatorname{Mn}(3) .^{53}$ The best-match models from this set of structures are summarised in Table 2; the full set of structures canvassed during these calculations is detailed in Table S1 (ESI $\dagger)$.

To assist in assessment of the reliability of various model structures as mimics for the Umena et $a{ }^{7}{ }^{7} \mathrm{XRD}$, we have listed, in Table 2 and Table S1 (ESI $\dagger$ ), the root-mean-square deviations (RMSD) of calculated $\mathrm{Mn}-\mathrm{Mn}$ and $\mathrm{Mn}-\mathrm{Ca}$ distances from those of the crystal structure. Perusal of these values suggest that each of the putative $S$ states $S_{0}-S_{3}$ has at least one possible model structure - invariably, one in which the $\mathrm{O}(4) / \mathrm{O}(5)$ bridging interaction between $\mathrm{Mn}(3)$ and $\mathrm{Mn}(4)$ involves at least one $\mathrm{OH}$ group - for which the RMSD for metal-metal bond distances is marginally lower than $0.1 \AA$. The best overall agreement (RMSD $=0.082 \AA$ (ferromagnetic coupling), $0.080 \AA$ (mean of three structures with antiferromagnetic coupling patterns)) is seen for a putative $\mathrm{S}_{3}$ state structure $\left(\mathrm{Mn}^{\mathrm{III}} \mathrm{Mn}^{\mathrm{IV}} \mathrm{Mn}^{\mathrm{IV}} \mathrm{Mn}^{\mathrm{III}}\right)$ with $\mathrm{O}(4)$ protonated, but the RMSD for the corresponding $\left(\mathrm{Mn}^{\mathrm{III}} \mathrm{Mn}^{\mathrm{III}} \mathrm{Mn}^{\mathrm{IV}} \mathrm{Mn}^{\mathrm{II}}\right) \mathrm{S}_{1}$ state structure is only slightly larger (0.087 $\AA$ ferromagnetic, $0.089 \AA$ mean antiferromagnetic). Both structures are depicted in Fig. 3. The slender difference in RMSD values for these two structures, differing by two Mn oxidation equivalents overall, is intriguing and, we suggest, insignificant in the face of the XRD distance uncertainties. It is generally considered that the 'resting state' of PSII attained in crystal structure determination is the $S_{1}$ state. Since $S_{3}$ in the 'PSII low oxidation paradigm' (which we adopt in the present work) is equivalent, in mean Mn oxidation state, to $S_{1}$ in the 'PSII high oxidation paradigm' (favoured by some other researchers in this field), it is worth noting that both paradigms fit the observed set of metal-metal distances in the Umena et al. $^{7}$ XRD about equally well. Further, for both $\mathrm{S}_{1}$ and $S_{3}$ the best fit to the XRD distances is found when $O(4)$ is protonated while $\mathrm{O}(5)$ remains unprotonated. Structures in which $\mathrm{O}(5)$ is protonated, rather than $\mathrm{O}(4)$, generally result in an overly-long $\mathrm{Mn}(1)-\mathrm{Mn}(4)$ distance, which also ensures that the $\mathrm{Ca}$ does not 'sit right' with respect to the other metal atoms; when both $\mathrm{O}(4)$ and $\mathrm{O}(5)$ are protonated, $\mathrm{Mn}(3)-\mathrm{Mn}(4)$ is consistently too long; when neither $\mathrm{O}(4)$ nor $\mathrm{O}(5)$ is protonated, $\mathrm{Mn}(3)-\mathrm{Mn}(4)$ is too short. After $\mathrm{S}_{1}$ and $\mathrm{S}_{3}$, the best geometries obtained for the ('low oxidation paradigm') $\mathrm{S}_{0}$ and $\mathrm{S}_{2}$ state structures (which would not generally be considered to represent the crystalline 'resting state') appear to less closely mimic the XRD vectors, particularly when consideration is given to agreement for both the ferromagnetic and antiferromagnetic geometries.

While it might be considered that evenhanded comparison of the metal-metal distances in this fashion is a useful measure of model adherence to the XRD structure, we argue that several of the metal-metal distances (those for which two Mn atoms are connected by a directly bridging $\mathrm{O}$ or $\mathrm{OH}$ ligand) are intrinsically less 'elastic' than are the 'long' metal-metal separations not directly bridged (here, $\mathrm{Mn}(1)-\mathrm{Mn}(4)$ and the $\mathrm{Mn}-\mathrm{Ca}$ distances). The structural justification for this division between different metal-metal vector types may be made by observing that $\mathrm{Mn}(1)$, $\mathrm{Mn}(2)$ and $\mathrm{Mn}(3)$ comprise a robust and reasonably rigidly connected unit, by virtue of their linkage via the tri- $\mu$-oxo bridge $\mathrm{O}(2)$; the 'dangler' ion $\mathrm{Mn}(4)$ shows considerably greater positional fluxionality, particularly relative to $\mathrm{Mn}(1)$ 
Table 2 Optimized metal-metal bond distances and deviation from the 1.9 A XRD parameters for some water-ligated 'truncated' models in the 'low-oxidation-state' paradigm ${ }^{a}$

\begin{tabular}{|c|c|c|c|c|c|c|c|}
\hline S state ${ }^{b}$ & $\mathrm{~S}_{0}$ & & $\mathrm{~S}_{1}$ & & $\mathrm{~S}_{3}$ & & (Umena et al. $1.9 \AA)^{k}$ \\
\hline$q^{c}$ & -2 & & -1 & & +1 & & \\
\hline $\mathrm{OSP}^{d}$ & 3332 & & 3342 & & 3443 & & \\
\hline $\mathrm{O}(4)^{e}$ & $\mathrm{O}$ & & $\mathrm{OH}$ & & $\mathrm{OH}$ & & \\
\hline $\mathrm{O}(5)^{e}$ & $\mathrm{OH}$ & & $\mathrm{O}$ & & $\mathrm{O}$ & & \\
\hline Coupling ${ }^{f}$ & $\mathrm{~F}$ & $\mathrm{AF}$ & $\mathrm{F}$ & $\mathrm{AF}$ & $\mathrm{F}$ & $\mathrm{AF}$ & \\
\hline$r(\mathrm{Mn}(1)-\mathrm{Mn}(2))^{g} / \AA$ & 2.887 & 2.848 & 2.764 & 2.744 & 2.782 & 2.774 & 2.80 \\
\hline$r(\mathrm{Mn}(2)-\mathrm{Mn}(3)) / \AA$ & 2.942 & 2.925 & 2.92 & 2.848 & 2.79 & 2.773 & 2.90 \\
\hline$r(\operatorname{Mn}(1)-\operatorname{Mn}(3)) / \AA$ & 3.406 & 3.427 & 3.292 & 3.329 & 3.313 & 3.322 & 3.30 \\
\hline$r(\mathrm{Mn}(3)-\mathrm{Mn}(4)) / \AA$ & 3.02 & 2.925 & 2.914 & 2.891 & 2.872 & 2.832 & 2.94 \\
\hline$r(\mathrm{Mn}(1)-\mathrm{Mn}(4)) / \AA$ & 5.101 & 4.964 & 5.056 & 5.049 & 4.815 & 4.865 & 4.98 \\
\hline$r(\mathrm{Mn}(1)-\mathrm{Ca}) / \AA$ & 3.665 & 3.664 & 3.426 & 3.425 & 3.513 & 3.543 & 3.49 \\
\hline$r(\mathrm{Mn}(2)-\mathrm{Ca}) / \AA$ & 3.166 & 3.164 & 3.251 & 3.213 & 3.256 & 3.251 & 3.33 \\
\hline$r(\mathrm{Mn}(3)-\mathrm{Ca}) / \AA$ & 3.522 & 3.538 & 3.213 & 3.234 & 3.505 & 3.503 & 3.43 \\
\hline$r(\mathrm{Mn}(4)-\mathrm{Ca}) / \AA$ & 3.885 & 3.794 & 3.855 & 3.829 & 3.862 & 3.827 & 3.80 \\
\hline RMSD (short) ${ }^{h}$ & 0.082 & 0.069 & 0.025 & 0.048 & 0.066 & 0.085 & \\
\hline $\operatorname{RMSD}(\text { long }+\mathrm{Ca})^{i}$ & 0.133 & 0.118 & 0.115 & 0.111 & 0.092 & 0.075 & \\
\hline RMSD (all) ${ }^{j}$ & 0.113 & 0.099 & 0.087 & 0.089 & 0.082 & 0.080 & \\
\hline
\end{tabular}

Notes: ${ }^{a}$ For all results for this structure type, refer to Table S1 (ESI $\dagger$ ). ${ }^{b}$ According to the 'low-oxidation-state' paradigm, in which $\mathrm{S}_{0}$ implies a $\mathrm{Mn}^{\mathrm{II}}\left(\mathrm{Mn}^{\mathrm{III}}\right)_{3}$ oxidation state distribution. ${ }^{c}$ Overall charge state of the indicated model structure. ${ }^{d}$ Oxidation state pattern found for the indicated structure. For example, '3332' denotes a complex in which $\mathrm{Mn}(1), \mathrm{Mn}(2)$ and $\mathrm{Mn}(3)$ are all $\mathrm{Mn}^{\mathrm{III}}, \mathrm{Mn}(4)$ is $\mathrm{Mn}^{\mathrm{II}}$. ${ }^{e} \operatorname{Identity}$ of the indicated $\mathrm{Mn}(3) /$ $\mathrm{Mn}(4)$ bridging species as either $\mu-\mathrm{O}$ or $\mu-\mathrm{OH}$. See structure (1). ${ }^{f}$ Magnetic coupling $(\mathrm{F}=$ fully ferromagnetic coupling; AF $=$ antiferromagnetic coupling. For antiferromagnetic coupling, the reported results are averaged from the 'AABB', 'ABAB', and 'ABBA' coupling patterns, where, for example, 'ABAB' denotes a complex in which $\operatorname{Mn}(1)$ is $\alpha$-spin-dominant, $\operatorname{Mn}(2) \beta$-spin-dominant, $\operatorname{Mn}(3) \alpha$-spin-dominant, and $M n(4) \beta$-spin dominant.). ${ }^{g} \mathrm{Mn}-\mathrm{Mn}$ distance between the indicated pair of $\mathrm{Mn}$ atoms. ${ }^{h}$ Root-mean-square deviation from the corresponding $1.9 \AA$ resolution XRD values for the directly-bridged $\mathrm{Mn}-\mathrm{Mn}$ distances (viz., $\mathrm{Mn}(1)-\mathrm{Mn}(2), \operatorname{Mn}(2)-\operatorname{Mn}(3), \operatorname{Mn}(1)-\operatorname{Mn}(3)$ and $\operatorname{Mn}(3)-\operatorname{Mn}(4))$. ${ }^{i}$ Root-mean-square deviation from the corresponding $1.9 \AA$ resolution XRD values for the $\mathrm{Mn}(1)-\mathrm{Mn}(4)$ and $\mathrm{Ca}-\mathrm{Mn}(n)$ distances. ${ }^{j}$ Root-mean-square deviation from the corresponding $1.9 \AA$ resolution XRD values for both 'short' and 'long' metal-metal distances. ${ }^{k}$ Distances obtained from the $1.9 \AA$ resolution XRD of Umena et l. $^{7}$ Results shown are the average of monomer A and monomer B values.

and $\mathrm{Mn}(2)$ (although it is connected firmly, by multiple bridges, to $\mathrm{Mn}(3)$ ); while the 'cubanoid capping unit' $\mathrm{Ca}$ is confined by the generally looser mechanism of ionic bonding to multiple $\mathrm{O}$ atoms, and therefore shows reasonable mobility. If we then regard those $\mathrm{Mn}-\mathrm{Mn}$ pairs connected by a discrete bridging $\mathrm{O}$ (or $\mathrm{OH}$ ) as being a more stringent set of XRD-derived distances (hereafter denoted as the set of 'short' metal-metal distances) than the 'long' vectors of $\mathrm{Mn}(1)-\mathrm{Mn}(4)$ and $\mathrm{Mn}(n)-\mathrm{Ca}$, we find that substantially the closest match to the XRD distances is shown by the $\mathrm{O}(4)$-protonated $\mathrm{Mn}^{\mathrm{III}} \mathrm{Mn}^{\mathrm{III}} \mathrm{Mn}^{\mathrm{IV}} \mathrm{Mn}^{\mathrm{II}} \mathrm{S}_{1}$ state structure (RMSD $=0.025 \AA$ (ferromagnetic), $0.048 \AA ̊$ (antiferromagnetic)). It may be considered significant that this $\mathrm{S}_{1}$ model, in both ferromagnetic and antiferromagnetic coupling modes, shows closer agreement with the (more rigid) 'short' distances than it does with the (more elastic) 'long' distances, suggesting that it or a close variant could indeed be the appropriate model for the WOC site in the $1.9 \AA$ Umena et $a .^{7}$ XRD. The $\mathrm{O}(4)$-protonated $\mathrm{Mn}^{\mathrm{III}} \mathrm{Mn}^{\mathrm{IV}} \mathrm{Mn}^{\mathrm{IV}} \mathrm{Mn}^{\mathrm{III}} \mathrm{S}_{3}$ state structure that performed very well for the overall metalmetal RMSD criterion also has usefully small deviations for the 'short' distances (RMSD $=0.066 \AA$ (ferromagnetic), $0.085 \AA$ (antiferromagnetic)). Thus, while focussing on the 'short' Mn-Mn distances for this set of models seems to favour the $\mathrm{O}(4)$-protonated $\mathrm{Mn}^{\mathrm{III}} \mathrm{Mn}^{\mathrm{III}} \mathrm{Mn}^{\mathrm{IV}} \mathrm{Mn}^{\mathrm{II}} \mathrm{S}_{1}$ state model, it should be acknowledged that the $\mathrm{Mn}^{\mathrm{III}} \mathrm{Mn}^{\mathrm{IV}} \mathrm{Mn}^{\mathrm{IV}} \mathrm{Mn}^{\mathrm{III}} \mathrm{S}_{3}$ state structure provides almost as good a fit to the metal-metal distances indicated by the XRD data.

\section{Second set of models}

The structures explored in Table 2 take as their precept the assumption that the ligating entities not explicitly part of the protein structure itself are water molecules, a supposition which, while plausible, is not necessarily correct. It is distinctly possible that either $\mathrm{W}(1)$ or $\mathrm{W}(2)$ is a hydroxide ligand rather than $\mathrm{H}_{2} \mathrm{O}$, and as these ligands appear from the XRD results to be directly coordinated to one of the WOC's Mn atoms (in both cases, $\mathrm{Mn}(4)$ ), their identity might be expected to have an influence on the pattern of $\mathrm{Mn}$ oxidation states in the WOC, and therefore on the Mn-Mn distances. (Other 'solvent' molecules identified in the XRD, again assumed to be water molecules, might have an indirect influence on Mn oxidation state patterns and metal-metal distances, but this would presumably be a lesser effect.) We have explored the influence of $\mathrm{W}(1)$ or $\mathrm{W}(2)$ deprotonation on WOC model geometries which closely match the XRD metal-metal distances, for (low oxidation paradigm) $\mathrm{S}_{1}$ in Table 3 , and Table S3 (ESI $\dagger$ ) (equivalent to the high-oxidation-state paradigm for $S_{1}$ ) in Table 4. A more extensive survey of such structures is presented in the ESI†, in Tables S2 and S3. These results show that, while substitution of either W(1) or W(2) by a hydroxide ligand is entirely feasible based on the resulting metal-metal distances, such substitution does not confer measurably better agreement with the crystal structure geometries. Thus, while deprotonation of one or other water ligand on $\mathrm{Mn}(4)$ is clearly a plausible feature of the $1.9 \AA$ WOC, the case for such a feature cannot be made on the basis of metal-metal distances alone. The 'best' $S_{1}$ structure from this set of calculations is depicted in Fig. 4.

We note also that, as with the structures given in Table 2, the 'short' metal-metal distances for deprotonated $\mathrm{S}_{3}$ variants tend to show poorer agreement with the $1.9 \AA \mathrm{XRD}$, but redeem themselves somewhat in mimicking the 'longer' metal-metal distances. 

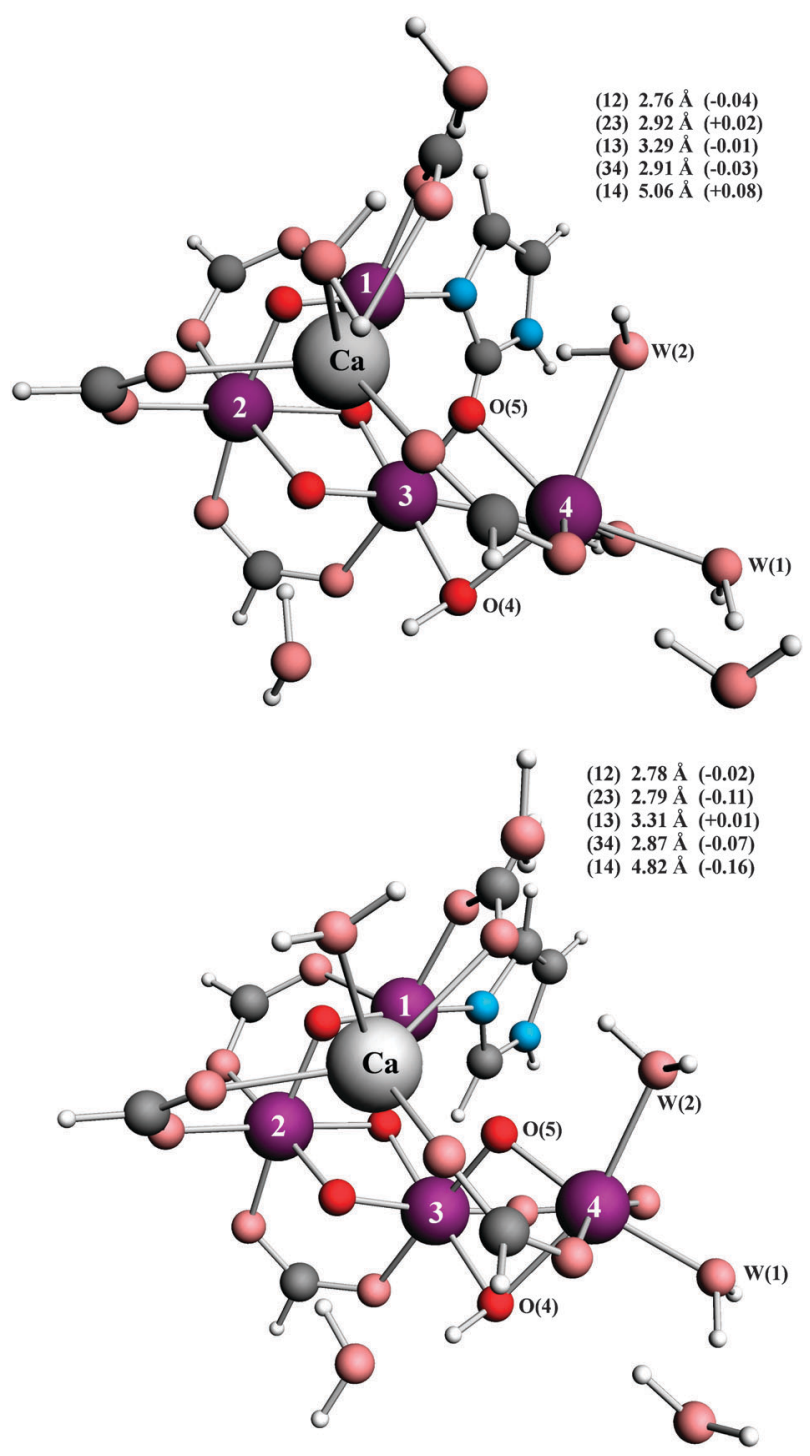

Fig. 3 The 'truncated' low-oxidation-state paradigm $\mathrm{S}_{1}\left(\mathrm{Mn}^{\mathrm{III}} \mathrm{Mn}^{\mathrm{III}}\right.$ $\left.\mathrm{Mn}^{\mathrm{IV}} \mathrm{Mn}^{\mathrm{II}}\right)$ and $\mathrm{S}_{3}\left(\mathrm{Mn}^{\mathrm{III}} \mathrm{Mn}^{\mathrm{IV}} \mathrm{Mn}^{\mathrm{IV}} \mathrm{Mn}^{\mathrm{III}}\right)$ models, optimised at the $\mathrm{BP} / \mathrm{TZP}$ level of theory, with $\mathrm{O}(4)=\mathrm{OH}, \mathrm{O}(5)=\mathrm{O}, \mathrm{W}(1)=\mathrm{W}(2)=$ $\mathrm{H}_{2} \mathrm{O}$. These models are found to deliver very good agreement with the metal-metal distances of the Umena et al. ${ }^{7} 1.9 \AA$ resolution XRD structure $(\mathrm{RMSD}=0.087 \AA, 0.082 \AA$ respectively). $\mathrm{Mn}-\mathrm{Mn}$ bond lengths obtained for these optimised geometries are indicated, alongside their deviations from the values obtained from the $1.9 \AA$ resolution XRD structure. $\mathrm{Mn}-\mathrm{Ca}$ distances and other details are given in Table 2. For clarity, the bonds between $\mathrm{Ca}$ and $\mathrm{O}(1), \mathrm{O}(3)$ and $\mathrm{O}(5)$ are not shown.

Most notable for the three 'best-fit' $S_{3}$ structure types in Tables 2 and 4 is that they all underestimate the $\operatorname{Mn}(2)-\operatorname{Mn}(3)$ distance by a margin of more than $0.1 \AA$, suggesting that this interaction is not well modelled as a $\mathrm{Mn}^{\mathrm{IV}} \mathrm{Mn}^{\mathrm{IV}}$ pairing.

In summary, the best hydroxide-substituted $S_{1}$ and $S_{3}$ structures (Tables 3 and 4) provide fits that are quite comparable to their water-ligated counterparts (Table 2); the difference between water- and hydroxide-ligated structures is too slight to provide a reliable indication of the nature of $\mathrm{W}(1)$ and $\mathrm{W}(2)$. Thus consideration should continue to be given to the possibility that one or other of these ligands is a hydroxide.

\section{Finessing the $\mathbf{O}(5)$ position}

Agreement with the $1.9 \AA$ resolution XRD metal-atom distances does not, of course, necessitate a complete match with every discernible characteristic of the crystal-structure of the WOC. Most challenging, in this regard, would seem to be rationalising the position of $\mathrm{O}(5)$, nominally bridging between $\mathrm{Mn}(3)$ and $\mathrm{Mn}(4)$ in our models but, in the crystal structure, near-equidistant from four metal atoms: $\operatorname{Mn}(1), \operatorname{Mn}(3), \operatorname{Mn}(4)$ and $\mathrm{Ca}$, at distances in the range $2.4-2.8 \AA$. The difficulty which this set of distances poses is that in none of the 'best eight' structural models (according to their adherence to the set of XRD metal-metal distances) as characterised in Tables 2-4 does the set of metal-O(5) distances have a RMSD error of less than $0.38 \AA$. This is illustrated in Table 5 where these distances are catalogued. For each of the surveyed structures, the worst metal- $\mathrm{O}(5)$ distance is out by at least $0.55 \AA$. In these models, $\mathrm{Mn}(1)$ is always significantly too far from $\mathrm{O}(5), \mathrm{Mn}(4)$ and $\mathrm{Ca}$ always significantly too close. In one structure, $\mathrm{Mn}(3)-\mathrm{O}(5)$ exceeds the crystallographic value by almost one Angstrom; in most other instances this distance is substantially too short. And this inability to appropriately localise $\mathrm{O}(5)$ is not restricted to the models highlighted in Table 5; none of the much larger set of surveyed structures in Tables S1-S3 (ESI $\dagger$ ) is significantly better. What makes the $\mathrm{O}(5)$ position so difficult to model?

There is, we would suggest, an apparent contradiction in the nature of $\mathrm{O}(5)$. The crystallographic value for $\mathrm{Mn}(3)-\mathrm{Mn}(4)$, of $2.94 \AA$, requires a connectivity comprising a carboxylate linkage (with this role taken by Glu333 in the WOC) and two oxo-based bridges, which according to our modelling is best accounted by one $\mu-\mathrm{O}$ and one $\mu-\mathrm{OH}$ bridge. It is not possible to say with certitude which of $\mathrm{O}(4)$ or $\mathrm{O}(5)$ is the hydroxo, based solely on the metal-atom distances: for the 'lowparadigm' $\left[\left(\mathrm{Mn}^{\mathrm{III}}\right)_{4}\right.$ or equivalent] definition of $\mathrm{S}_{1}$ which we favour, the metal-metal distances can be fitted almost equally well with $\mathrm{O}(4)$ or $\mathrm{O}(5)$ as hydroxo; while for the 'highparadigm' $\left[\left(\mathrm{Mn}^{\mathrm{III}}\right)_{2}\left(\mathrm{Mn}^{\mathrm{IV}}\right)_{2}\right]$ definition of $\mathrm{S}_{1}$, it would appear that $\mathrm{O}(4)$ is the 'preferred' candidate for a hydroxo bridge. However, neither 'oxo' nor 'hydroxo' provides a convincing fit for the position of $\mathrm{O}(5)$, despite serving well (in the Table 5 models) for the set of metal atom positions. We would go further and say that, based on the results detailed in Tables S1-S3 (ESI $\dagger$ ) $\mathrm{O}(5)$ cannot be either a $\mu-\mathrm{O}$ or a $\mu-\mathrm{OH}$ bridge. Where does this leave us?

The logical inference is that $\mathrm{O}(5)$ is most probably a water ligand, which suggestion would be superficially consistent with the set of metal-O(5) distances all exceeding $2.35 \AA$; but structures involving placement of a water ligand at the $\mathrm{O}(5)$ position invariably result in $\mathrm{Mn}(3)-\mathrm{Mn}$ (4) distances which are at least $0.20 \AA$ too long (with concomintant distortion of other metal-metal bonds also, most notably $\mathrm{Mn}(1)-\mathrm{Mn}(4))$, as well as an ' $\mathrm{O}(5)$ ' water ligand which wanders substantially too far from one or more of the four metal atoms to which it is nominally coordinated. We thus have the situation that $\mathrm{O}(5)$ as a hydroxide hugs too close to one or more $\mathrm{Mn}$ atoms, 
Table 3 Metal-metal bond distances and $\mathrm{Mn}$ atom spin densities for some hydroxide-ligated $\mathrm{S}_{1}$ state 'truncated' models in the 'low-oxidationstate' paradigm $^{a, b}$

\begin{tabular}{|c|c|c|c|c|c|c|c|}
\hline$q^{c}$ & -2 & & -2 & & -2 & & (Umena et al. $1.9 \AA$ ) \\
\hline $\mathrm{OSP}^{d}$ & 3333 & & 3342 & & 3333 & & \\
\hline $\mathrm{O}(4)^{e}$ & $\mathrm{O}$ & & $\mathrm{OH}$ & & $\mathrm{O}$ & & \\
\hline $\mathrm{O}(5)^{e}$ & $\mathrm{OH}$ & & $\mathrm{O}$ & & $\mathrm{OH}$ & & \\
\hline $\mathrm{W}(\mathrm{OH}) ?^{f}$ & (1) & & (2) & & (2) & & \\
\hline Coupling ${ }^{g}$ & $\mathrm{~F}$ & $\mathrm{AF}$ & $\mathrm{F}$ & $\mathrm{AF}$ & $\mathrm{F}$ & $\mathrm{AF}$ & \\
\hline$r(\mathrm{Mn}(1)-\mathrm{Mn}(2))^{h} / \AA$ & 2.896 & 2.870 & 2.762 & 2.720 & 2.890 & 2.861 & 2.80 \\
\hline$r(\operatorname{Mn}(2)-\operatorname{Mn}(3)) / \AA$ & 2.947 & 2.928 & 2.904 & 2.868 & 2.943 & 2.920 & 2.90 \\
\hline$r(\mathrm{Mn}(1)-\mathrm{Mn}(3)) / \AA$ & 3.307 & 3.319 & 3.234 & 3.364 & 3.305 & 3.324 & 3.30 \\
\hline$r(\mathrm{Mn}(3)-\mathrm{Mn}(4)) / \AA$ & 2.963 & 2.986 & 2.947 & 2.873 & 2.966 & 3.013 & 2.94 \\
\hline$r(\mathrm{Mn}(1)-\mathrm{Mn}(4)) / \AA$ & 5.138 & 5.108 & 4.811 & 5.094 & 5.076 & 5.033 & 4.98 \\
\hline$r(\mathrm{Mn}(1)-\mathrm{Ca}) / \mathrm{A}$ & 3.478 & 3.470 & 3.388 & 3.434 & 3.474 & 3.531 & 3.49 \\
\hline$r(\mathrm{Mn}(2)-\mathrm{Ca}) / \AA$ & 3.193 & 3.195 & 3.274 & 3.215 & 3.201 & 3.183 & 3.33 \\
\hline$r(\mathrm{Mn}(3)-\mathrm{Ca}) / \AA$ & 3.397 & 3.402 & 3.168 & 3.200 & 3.421 & 3.442 & 3.43 \\
\hline$r(\mathrm{Mn}(4)-\mathrm{Ca}) / \AA$ & 3.764 & 3.764 & 3.746 & 3.857 & 3.759 & 3.783 & 3.80 \\
\hline $\operatorname{RMSD}(\text { short })^{i}$ & 0.055 & 0.045 & 0.038 & 0.063 & 0.052 & 0.050 & \\
\hline RMSD $(\text { long }+\mathrm{Ca})^{j}$ & 0.096 & 0.086 & 0.151 & 0.131 & 0.075 & 0.073 & \\
\hline RMSD (all) ${ }^{k}$ & 0.080 & 0.071 & 0.115 & 0.106 & 0.065 & 0.064 & \\
\hline
\end{tabular}

Notes: ${ }^{a}$ According to the 'low-oxidation-state' paradigm, in which $\mathrm{S}_{1}$ implies an oxidation state distribution of $\left(\mathrm{Mn}^{\mathrm{III}}\right)_{4}$ or equivalent. ${ }^{b}$ For all results for this structure type, refer to Table S2 (ESI $\dagger)$. ${ }^{c}$ Overall charge state of the indicated model structure. ${ }^{d}$ Oxidation state pattern found for the indicated structure. For example, '3332' denotes a complex in which $\mathrm{Mn}(1), \mathrm{Mn}(2)$ and $\mathrm{Mn}(3)$ are all $\mathrm{Mn}^{\mathrm{III}}, \mathrm{Mn}(4)$ is $\mathrm{Mn}^{\mathrm{II}}$. ${ }^{e} \mathrm{Identity}$ of the indicated $\mathrm{Mn}(3) / \mathrm{Mn}(4)$ bridging species as either $\mu-\mathrm{O}$ or $\mu-\mathrm{OH}$. See structure (1). ${ }^{f}$ Identity of either 'W(1)' or 'W(2)' as a hydroxide ligand. See structure (1). ${ }^{g}$ Magnetic coupling ( $\mathrm{F}=$ fully ferromagnetic coupling; AF = antiferromagnetic coupling. For antiferromagnetic coupling, the reported results are averaged from the 'AABB', 'ABAB', and 'ABBA' coupling patterns, where, for example, 'ABAB' denotes a complex in which $\operatorname{Mn}(1)$ is $\alpha$-spin-dominant, $\operatorname{Mn}(2) \beta$-spin-dominant, $\operatorname{Mn}(3) \alpha$-spin-dominant, and $\operatorname{Mn}(4) \beta$-spin dominant.). ${ }^{h} \mathrm{Mn}-\mathrm{Mn}$ distance between the indicated pair of Mn atoms. ${ }^{i}$ Root-mean-square deviation from the corresponding $1.9 \AA$ resolution XRD values for the directly-bridged Mn-Mn distances (viz., $\mathrm{Mn}(1)-\mathrm{Mn}(2), \mathrm{Mn}(2)-\mathrm{Mn}(3), \mathrm{Mn}(1)-\mathrm{Mn}(3)$ and $\mathrm{Mn}(3)-\mathrm{Mn}(4)) .{ }^{j}$ Root-mean-square deviation from the corresponding $1.9 \AA$ resolution XRD values for the $\mathrm{Mn}(1)-\mathrm{Mn}(4)$ and $\mathrm{Ca}-\mathrm{Mn}(n)$ distances. ${ }^{k}$ Root-mean-square deviation from the corresponding $1.9 \AA$ resolution XRD values for both 'short' and 'long' metal-metal distances. ${ }^{l}$ Distances obtained from the $1.9 \AA$ resolution XRD of Umena et al. ${ }^{7}$ Results shown are the average of monomer A and monomer B values.

Table 4 Metal-metal bond distances and Mn atom spin densities for some 'minimal hydroxide-ligated $\mathrm{S}_{3}$ state 'truncated' models in the 'low-oxidation-state' paradigm ${ }^{a, b}$

\begin{tabular}{|c|c|c|c|c|c|}
\hline$q^{c}$ & 0 & & 0 & & (Umena et al. $1.9 \AA)^{l}$ \\
\hline $\mathrm{OSP}^{d}$ & 3443 & & 3443 & & \\
\hline $\mathrm{O}(4)^{e}$ & $\mathrm{OH}$ & & $\mathrm{OH}$ & & \\
\hline $\mathrm{O}(5)^{e}$ & $\mathrm{O}$ & & $\mathrm{O}$ & & \\
\hline $\mathrm{W}(\mathrm{OH}) ?^{f}$ & (1) & & (2) & & \\
\hline Coupling ${ }^{g}$ & $\mathrm{~F}$ & $\mathrm{AF}$ & $\mathrm{F}$ & $\mathrm{AF}$ & \\
\hline$r(\mathrm{Mn}(1)-\mathrm{Mn}(2))^{h} / \AA$ & 2.768 & 2.758 & 2.77 & 2.758 & 2.80 \\
\hline$r(\mathrm{Mn}(2)-\mathrm{Mn}(3)) / \AA$ & 2.793 & 2.781 & 2.794 & 2.787 & 2.90 \\
\hline$r(\operatorname{Mn}(1)-\operatorname{Mn}(3)) / \AA$ & 3.327 & 3.34 & 3.265 & 3.309 & 3.30 \\
\hline$r(\operatorname{Mn}(3)-\operatorname{Mn}(4)) / \AA$ & 2.834 & 2.817 & 2.846 & 2.831 & 2.94 \\
\hline$r(\mathrm{Mn}(1)-\mathrm{Mn}(4)) / \AA$ & 5.109 & 5.13 & 4.805 & 4.94 & 4.98 \\
\hline$r(\mathrm{Mn}(1)-\mathrm{Ca}) / \AA$ & 3.482 & 3.5 & 3.489 & 3.516 & 3.49 \\
\hline$r(\mathrm{Mn}(2)-\mathrm{Ca}) / \mathrm{A}$ & 3.284 & 3.286 & 3.265 & 3.262 & 3.33 \\
\hline$r(\mathrm{Mn}(3)-\mathrm{Ca}) / \AA$ & 3.393 & 3.384 & 3.433 & 3.432 & 3.43 \\
\hline$r(\mathrm{Mn}(4)-\mathrm{Ca}) / \mathrm{A}$ & 3.712 & 3.725 & 3.695 & 3.755 & 3.80 \\
\hline $\operatorname{RMSD}(\text { short })^{i}$ & 0.078 & 0.09 & 0.074 & 0.081 & \\
\hline RMSD $(\text { long }+\mathrm{Ca})^{j}$ & 0.075 & 0.08 & 0.096 & 0.042 & \\
\hline RMSD (all) $)^{k}$ & 0.076 & 0.085 & 0.087 & 0.063 & \\
\hline
\end{tabular}

Notes: ${ }^{a}$ According to the 'low-oxidation-state' paradigm, in which $\mathrm{S}_{3}$ implies an oxidation state distribution of $\left(\mathrm{Mn}^{\mathrm{III}}\right)_{2}\left(\mathrm{Mn}^{\mathrm{IV}}\right)_{2}$ or equivalent. ${ }^{b}$ For all results for this structure type, refer to Table S3 (ESI $\dagger$ ). ${ }^{c}$ Refer notes $c-l$ for Table 3 , and structure (1).

$\mathrm{O}(5)$ as a water ligand sits too far out. Can $\mathrm{O}(5)$, therefore, be something between a hydroxide and a water ligand, such as a substantially activated $\mathrm{H}_{2} \mathrm{O}$ species, with one of the water ligand's protons shared with a neighbouring ligand? While such a possibility is very difficult to model within the

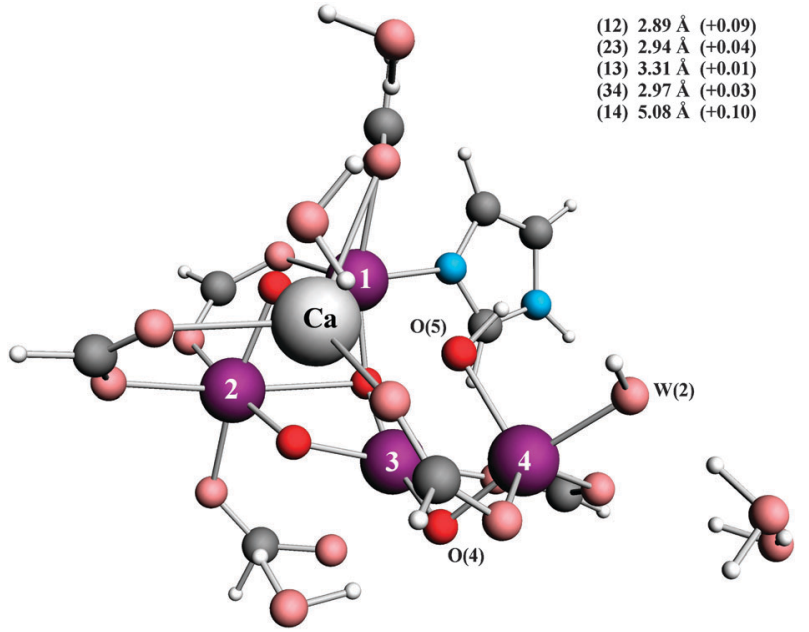

Fig. 4 The 'truncated' low-oxidation-state paradigm $\mathrm{S}_{1}\left(\mathrm{Mn}^{\mathrm{III}} \mathrm{M}\right.$ $\mathrm{n}^{\mathrm{III}} \mathrm{Mn}^{\mathrm{III}} \mathrm{Mn}^{\mathrm{III}}$ ) model, optimised at the BP/TZP level of theory, with $\mathrm{O}(4)=\mathrm{O}, \mathrm{O}(5)=\mathrm{OH}, \mathrm{W}(2)=\mathrm{OH}$. This model also delivers extremely good agreement with the metal-metal distances of the Umena et $a l^{7} 1.9 \AA$ resolution XRD structure (RMSD $=0.065 \AA$ ). $\mathrm{Mn}-\mathrm{Mn}$ bond lengths obtained for these optimised geometries are indicated, alongside their deviations from the values obtained from the 1.9 A resolution XRD structure $\mathrm{Mn}-\mathrm{Ca}$ distances and other details are given in Table 3. For clarity, the bonds between $\mathrm{Ca}$ and $\mathrm{O}(1), \mathrm{O}(3)$ and $\mathrm{O}(5)$ are not shown.

restrictions of our 'truncated' models for the PSII WOC (in which the solvent 'pockets' cannot be adequately defined), it is 
Table 5 Optimized $\mathrm{O}(5)-$ metal bond distances and deviation from the $1.9 \AA$ XRD parameters for the models ('low-oxidation-state' paradigm) featured in Tables $2-4^{a}$

\begin{tabular}{|c|c|c|c|c|c|c|c|c|c|c|c|c|c|}
\hline \multirow[b]{2}{*}{$\begin{array}{l}\text { S state }{ }^{b} \\
\text { Shen } 1.9 \AA^{k}\end{array}$} & \multirow[b]{2}{*}{$q^{c}$} & \multirow[b]{2}{*}{$\mathrm{O}(4)^{d}$} & \multirow[b]{2}{*}{$\mathrm{O}(5)^{d}$} & \multirow[b]{2}{*}{$\mathrm{W}(\mathrm{OH} ?)^{e}$} & \multirow[b]{2}{*}{ Coupling ${ }^{f}$} & \multirow[b]{2}{*}{ OSP $^{g}$} & \multicolumn{4}{|c|}{$r(\mathrm{O}(5)-\mathrm{M}) / \AA$} & \multicolumn{3}{|l|}{ RMSD } \\
\hline & & & & & & & $\begin{array}{l}\operatorname{Mn}(1) \\
2.60\end{array}$ & $\begin{array}{l}\operatorname{Mn}(3) \\
2.40\end{array}$ & $\begin{array}{l}\operatorname{Mn}(4) \\
2.47\end{array}$ & $\begin{array}{l}\mathrm{Ca} \\
2.80\end{array}$ & $(\mathrm{M}-\mathrm{M})^{h}$ & $(\mathrm{O}-\mathrm{M})^{i}$ & $(\mathrm{All})^{j}$ \\
\hline$\overline{\mathrm{S}_{0}}$ & -2 & $\mathrm{O}$ & $\mathrm{OH}$ & - & $\begin{array}{l}\mathrm{F} \\
\mathrm{AF}\end{array}$ & 3332 & $\begin{array}{l}3.804 \\
3.769\end{array}$ & $\begin{array}{l}3.254 \\
3.328\end{array}$ & $\begin{array}{l}2.113 \\
2.102\end{array}$ & $\begin{array}{l}2.375 \\
2.367\end{array}$ & $\begin{array}{l}0.113 \\
0.099\end{array}$ & $\begin{array}{l}0.778 \\
0.788\end{array}$ & $\begin{array}{l}0.441 \\
0.445\end{array}$ \\
\hline $\mathrm{S}_{1}$ & -1 & $\mathrm{OH}$ & $\mathrm{O}$ & - & $\begin{array}{l}\mathrm{F} \\
\mathrm{AF}\end{array}$ & 3342 & $\begin{array}{l}2.980 \\
3.018\end{array}$ & $\begin{array}{l}1.832 \\
1.834\end{array}$ & $\begin{array}{l}2.115 \\
2.071\end{array}$ & $\begin{array}{l}2.418 \\
2.412\end{array}$ & $\begin{array}{l}0.087 \\
0.089\end{array}$ & $\begin{array}{l}0.396 \\
0.416\end{array}$ & $\begin{array}{l}0.231 \\
0.242\end{array}$ \\
\hline $\mathrm{S}_{3}$ & +1 & $\mathrm{OH}$ & $\mathrm{O}$ & - & $\begin{array}{l}\mathrm{F} \\
\mathrm{AF}\end{array}$ & 3342 & $\begin{array}{l}3.065 \\
3.055\end{array}$ & $\begin{array}{l}1.876 \\
1.866\end{array}$ & $\begin{array}{l}1.824 \\
1.814\end{array}$ & $\begin{array}{l}2.568 \\
2.574\end{array}$ & $\begin{array}{l}0.082 \\
0.080\end{array}$ & $\begin{array}{l}0.476 \\
0.479\end{array}$ & $\begin{array}{l}0.273 \\
0.274\end{array}$ \\
\hline $\mathrm{S}_{1}$ & -2 & $\mathrm{O}$ & $\mathrm{OH}$ & (1) & $\begin{array}{l}\mathrm{F} \\
\mathrm{AF}\end{array}$ & 3333 & $\begin{array}{l}3.335 \\
3.352\end{array}$ & $\begin{array}{l}2.525 \\
2.627\end{array}$ & $\begin{array}{l}2.023 \\
2.015\end{array}$ & $\begin{array}{l}2.381 \\
2.376\end{array}$ & $\begin{array}{l}0.080 \\
0.071\end{array}$ & $\begin{array}{l}0.457 \\
0.478\end{array}$ & $\begin{array}{l}0.262 \\
0.271\end{array}$ \\
\hline $\mathrm{S}_{1}$ & -2 & $\mathrm{OH}$ & $\mathrm{O}$ & (2) & $\begin{array}{l}\mathrm{F} \\
\mathrm{AF}\end{array}$ & 3342 & $\begin{array}{l}2.797 \\
3.093\end{array}$ & $\begin{array}{l}1.818 \\
1.803\end{array}$ & $\begin{array}{l}2.069 \\
2.043\end{array}$ & $\begin{array}{l}2.380 \\
2.417\end{array}$ & $\begin{array}{l}0.115 \\
0.106\end{array}$ & $\begin{array}{l}0.384 \\
0.452\end{array}$ & $\begin{array}{l}0.234 \\
0.266\end{array}$ \\
\hline $\mathrm{S}_{1}$ & -2 & $\mathrm{O}$ & $\mathrm{OH}$ & (2) & $\begin{array}{l}\mathrm{F} \\
\mathrm{AF}\end{array}$ & 3333 & $\begin{array}{l}3.260 \\
3.323\end{array}$ & $\begin{array}{l}2.523 \\
2.668\end{array}$ & $\begin{array}{l}2.020 \\
1.987\end{array}$ & $\begin{array}{l}2.385 \\
2.384\end{array}$ & $\begin{array}{l}0.065 \\
0.064\end{array}$ & $\begin{array}{l}0.428 \\
0.478\end{array}$ & $\begin{array}{l}0.243 \\
0.270\end{array}$ \\
\hline $\mathrm{S}_{3}$ & 0 & $\mathrm{OH}$ & $\mathrm{O}$ & (1) & $\begin{array}{l}\mathrm{F} \\
\mathrm{AF}\end{array}$ & 3443 & $\begin{array}{l}3.143 \\
3.192\end{array}$ & $\begin{array}{l}1.805 \\
1.806\end{array}$ & $\begin{array}{l}1.981 \\
1.959\end{array}$ & $\begin{array}{l}2.458 \\
2.446\end{array}$ & $\begin{array}{l}0.076 \\
0.085\end{array}$ & $\begin{array}{l}0.476 \\
0.497\end{array}$ & $\begin{array}{l}0.272 \\
0.285\end{array}$ \\
\hline $\mathrm{S}_{3}$ & 0 & $\mathrm{OH}$ & $\mathrm{O}$ & (2) & $\begin{array}{l}\mathrm{F} \\
\mathrm{AF}\end{array}$ & 3443 & $\begin{array}{l}2.914 \\
3.068\end{array}$ & $\begin{array}{l}1.837 \\
1.827\end{array}$ & $\begin{array}{l}1.923 \\
1.902\end{array}$ & $\begin{array}{l}2.508 \\
2.526\end{array}$ & $\begin{array}{l}0.087 \\
0.063\end{array}$ & $\begin{array}{l}0.425 \\
0.467\end{array}$ & $\begin{array}{l}0.246 \\
0.264\end{array}$ \\
\hline
\end{tabular}

Notes: ${ }^{a}$ For all results for this structure type, refer to Table S1 (ESI $\dagger$ ). ${ }^{b}$ According to the 'low-oxidation-state’ paradigm, in which $\mathrm{S}_{0}$ implies a $\mathrm{Mn}^{\mathrm{II}}\left(\mathrm{Mn}^{\mathrm{III}}\right)_{3}$ oxidation state distribution. ${ }^{c}$ Overall charge state of the indicated model structure. ${ }^{d}$ Identity of the indicated $\mathrm{Mn}(3) / \mathrm{Mn}(4)$ bridging species as either $\mu-\mathrm{O}$ or $\mu-\mathrm{OH}$. See structure (1). ${ }^{e}$ Identity of either 'W(1)' or 'W(2)' as a hydroxide ligand. See structure (1). ${ }^{f}$ Magnetic coupling $(\mathrm{F}=$ fully ferromagnetic coupling; $\mathrm{AF}=$ antiferromagnetic coupling. For antiferromagnetic coupling, the reported results are averaged from the 'AABB', 'ABAB', and 'ABBA' coupling patterns, where, for example, 'ABAB' denotes a complex in which Mn(1) is $\alpha$-spin-dominant, Mn(2) $\beta$-spin-dominant, $\operatorname{Mn}(3) \alpha$-spin-dominant, and $\operatorname{Mn}(4) \beta$-spin dominant.). ${ }^{g}$ Oxidation state pattern found for the indicated structure. For example, ' 3332 ' denotes a complex in which $\mathrm{Mn}(1), \mathrm{Mn}(2)$ and $\mathrm{Mn}(3)$ are all $\mathrm{Mn}^{\mathrm{III}}, \mathrm{Mn}(4)$ is $\mathrm{Mn}^{\mathrm{II}} .{ }^{h}$ Root-mean-square deviation from the corresponding $1.9 \AA$ A resolution XRD values for both 'short' and 'long' metal-metal distances (see Table 2). ${ }^{i}$ RMSD from the corresponding $1.9 \AA$ resolution XRD values for O(5)-metal distances. ${ }^{j}$ RMSD from the corresponding $1.9 \AA$ resolution XRD values for the combined set of metal-metal and $\mathrm{O}(5)$-metal distances. ${ }^{k}$ Distances obtained from the $1.9 \AA$ resolution XRD of Umena et al. ${ }^{7}$ Results shown are the average of monomer A and monomer B values.

an option which we are pursuing in more extended model calculations.

\section{Calculations on an extended model}

Given the importance of modelling the protein environment immediately enveloping the $\mathrm{CaMn}_{4}$ cluster, we have initiated a series of calculations in which the peptide chain His332, Glu333, Arg334, Asn335, Ala336, His337, Asn338, Phe339, Pro340, Leu341, Asp342, Leu343, Ala344 is explicitly included, with amino acid $\alpha$ carbons pinned at their crystallographic positions corresponding to the $2.9 \AA$ XRD structure $^{6}$ so as to minimise conformational wandering. As previously noted, ${ }^{40}$ our calculations on these 'extended' models treat the $\mathrm{CaMn}_{4} \mathrm{O}_{5}$ core using TZP basis sets while DZP basis sets are employed for other atoms.

Of several structures thus far investigated, the best agreement with the Umena et al. XRD geometry ${ }^{7}$ from our 'extended' models is for a low-oxidation-state paradigm $\mathrm{S}_{1}$ structure $\left(\mathrm{Mn}^{\mathrm{III}} \mathrm{Mn}^{\mathrm{III}} \mathrm{Mn}^{\mathrm{III}} \mathrm{Mn}^{\mathrm{III}}\right)$ for which the RMSD value for 'short' metal-metal distances is $0.048 \AA$, and the RMSD value across all metal-metal distances is $0.114 \AA$. This structure is shown in Fig. 5. The close agreement for the crucial
$\operatorname{Mn}(1)-\operatorname{Mn}(2), \quad M n(2)-\operatorname{Mn}(3), \quad M n(1)-\operatorname{Mn}(3)$ and $\operatorname{Mn}(3)$ $\mathrm{Mn}(4)$ distances indicates that the important features of metal-metal interaction indicated by the $1.9 \AA$ resolution XRD structure can be satisfactorily modelled by a more realistic 'extended' model as well as by the more computationally tractable 'truncated' models described in the previous sections of the present work.

\section{Comparison with other theoretical studies}

Several other theoretical studies ${ }^{19,31,33,35-37,40}$ have employed DFT to assess and to model the $1.9 \AA$ XRD structure. ${ }^{7}$ Results from these studies ${ }^{54}$ are represented in Table 6 alongside the 'best' low-oxidation-state (LOS) paradigm $\mathrm{S}_{0}-\mathrm{S}_{3}$ structures from the present work.

Definition of the appropriate oxidation state paradigm is important in comparing the structures summarised in Table 6. Notably, most other research groups ${ }^{19,31,33,35-38}$ have adopted the 'high-oxidation-state' (HOS) paradigm, while our own work assumes the LOS paradigm. As a consequence, the structures in Table 6 range across five overall oxidation levels, from $\mathrm{Mn}^{\mathrm{II}}\left(\mathrm{Mn}^{\mathrm{III}}\right)_{3}\left[\mathrm{LOS} \mathrm{S}_{0}\right.$ or HOS S $\mathrm{H}_{-2}$ ] to $\mathrm{Mn}^{\mathrm{III}}\left(\mathrm{Mn}^{\mathrm{IV}}\right)_{3}\left[\mathrm{LOS} \mathrm{S} \mathrm{S}_{4}\right.$ or $\mathrm{HOS}_{2}$ ]. Results reported by other groups have variously adopted 


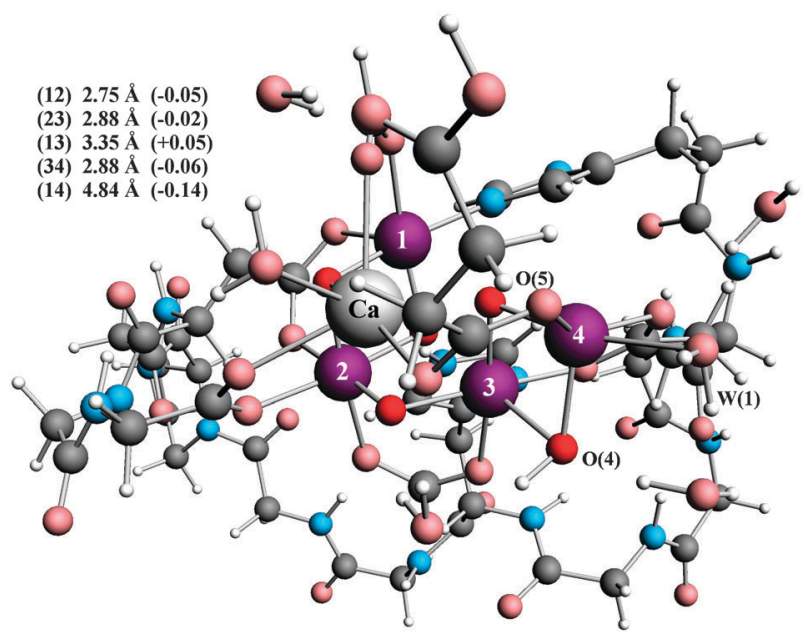

Fig. 5 The 'extended' low-oxidation-state paradigm $\mathrm{S}_{1}$ model, optimised at the $\mathrm{BP} / \mathrm{TZP} / \mathrm{DZP}$ level of theory, with $\mathrm{O}(4)=\mathrm{OH}, \mathrm{O}(5)=\mathrm{O}, \mathrm{W}(1)=$ $\mathrm{H}_{2} \mathrm{O}$. While this model does not deliver such close agreement with the metal-metal distances of the Umena et al. ${ }^{7} 1.9$ A resolution XRD structure ( $\mathrm{RMSD}=0.114 \AA$ ) as is provided by the 'truncated' models depicted in Fig. 3 and 4, its performance for the set of four 'short' Mn-Mn distances $(\mathrm{Mn}(1)-\mathrm{Mn}(2), \mathrm{Mn}(2)-\mathrm{Mn}(3), \mathrm{Mn}(1)-\mathrm{Mn}(3), \mathrm{Mn}(3)-\mathrm{Mn}(4))$ is very good ( $\mathrm{RMSD}=0.048 \AA$ ). . Mn-Mn bond lengths obtained for these optimised geometries are indicated, alongside their deviations from the values obtained from the $1.9 \AA$ resolution XRD structure $\mathrm{Mn}-\mathrm{Ca}$ distances and other details are given in Table 6. For clarity, the bonds between $\mathrm{Ca}$ and $\mathrm{O}(1), \mathrm{O}(3)$ and $\mathrm{O}(5)$ are not shown.

ferromagnetic or antiferromagnetic coupling patterns (or in some instances have not declared which mode of magnetic coupling has been explored). From our own computed results, the structures reported in Table 6 are ferromagnetically coupled, although the conclusions drawn would not be significantly influenced if the antiferromagnetic configurations had been included instead.

How do the various structures listed in Table 6 perform? Assuming that the most stringent test for characterising the metal-metal distances is the determination of the 'short' $\mathrm{Mn}-\mathrm{Mn}$ bonds, all of the models derive reasonable $\mathrm{Mn}(1)-\mathrm{Mn}(2)$ distances: none of the Table 6 models gives a value which differs from the experimental measure of $2.80 \AA$ by more than $0.09 \AA$, the 'scatter' is evenly distributed to the low and high sides of the experimental value. This can be contrasted with the results for $\operatorname{Mn}(2)-\operatorname{Mn}(3)$, for which the only models which give a value within $0.09 \AA$ of the experimental result of $2.90 \AA$ are our $\mathrm{S}_{0}-\mathrm{S}_{2}$ (LOS) models. All of the models with a $\mathrm{S}_{3}$ (LOS) - equivalent to $\mathrm{S}_{1}$ (HOS) - configuration underestimate this distance by between 0.1 and $0.2 \AA$, and the $\mathrm{S}_{0}$ (HOS) model of Siegbahn ${ }^{31}$ also significantly underestimates it. The XRD Mn(1)-Mn(3) distance of $3.30 \AA$ is well-matched by several models across virtually the full range of represented oxidation states, and several models, again across a range of oxidation states, also yield $\mathrm{Mn}(3)-\mathrm{Mn}(4)$ distances close to the XRD value of $2.94 \AA$. Analysed across this set of four Mn-Mn separations, the three models which remain closest to the crystallographic distances are the three $S_{1}$ (LOS) geometries from the present work, with our 'best' $\mathrm{S}_{3}$ (LOS) model taking fourth place. Three of these models are also the closest three fits when the 'expanded set' of metal-metal distances, including also $\mathrm{Mn}(1)-\mathrm{Mn}(4)$ and the four $\mathrm{Mn}-\mathrm{Ca}$ distances, is considered. Finally and importantly, the metal-metal distances can be faithfully matched by a stand-alone $S_{1}$ structure, regardless of whether the LOS or HOS paradigm is adopted

\section{Conclusions}

Density functional theory calculations on models of the most recent 1.9 A resolution XRD of Photosystem $\mathrm{II}^{7}$ reveal several important aspects of the new XRD geometry: while the $\operatorname{Mn}(1)-\operatorname{Mn}(2)$ and $\operatorname{Mn}(2)-\operatorname{Mn}(3)$ distances within this structure are appreciably longer than had been previously determined by single-crystal X-ray diffraction or EXAFS, the new distances can be satisfactorily modelled by structures in which $\operatorname{Mn}(2)$ is in the III oxidation state and the $\mu_{3}$-oxo bridge $(\mathrm{O}(2))$ is unprotonated. This appears to be a robust conclusion, consistent with the range of oxidation/protonation state possibilities examined, but is certainly different from the preferred oxidation state pattern for $\mathrm{S}_{1}$ previously identified by us (3432), ${ }^{9}$ which gives a good match to the $\operatorname{Mn}(1)-\operatorname{Mn}(2)$ and $\mathrm{Mn}(2)-\mathrm{Mn}(3)$ distances inferred from EXAFS etc. In addition, the 'short' $\mathrm{Mn}(3)-\mathrm{Mn}(4)$ distance of the new XRD result is consistent with a bridging arrangement between these two $\mathrm{Mn}$ atoms involving one carboxylate, one $\mu-\mathrm{O}$, and one $\mu-\mathrm{OH}$ bridge. Best agreement with the 'short' $\mathrm{Mn}-\mathrm{Mn}$ distances overall is obtained for a low-oxidation-state paradigm $\left(\left(\mathrm{Mn}^{\mathrm{III}}\right)_{4}\right.$ or $\left.\mathrm{Mn}^{\mathrm{II}}\left(\mathrm{Mn}^{\mathrm{III}}\right)_{2} \mathrm{Mn}^{\mathrm{IV}}\right) \mathrm{S}_{1}$ structure - the agreement offered by a high-oxidation-state paradigm $\mathrm{S}_{1}\left(\left(\mathrm{Mn}^{\mathrm{III}}\right)_{2}\left(\mathrm{Mn}^{\mathrm{IV}}\right)_{2}\right.$, equivalent also to the $\mathrm{S}_{3}$ state of the low-oxidation-state paradigm) is somewhat poorer. Substitution of water ligands on $\mathrm{Mn}(4)$ by hydroxide is observed to have subtle structural implications for the model structures: the metal-metal distances of the new XRD can be well matched either with or without $\mathrm{Mn}(4)$ hydroxide ligation, so the identity of the $\mathrm{Mn}(4)$ ligands $\mathrm{W}(1)$ and $\mathrm{W}(2)$ remains uncertain. ${ }^{57}$ The identity of the $\mathrm{Mn}(3) / \mathrm{Mn}(4)$ bridging species $\mathrm{O}(5)$ also remains problematic: while good agreement with the metal-metal distances can be obtained if $\mathrm{O}(5)$ is an oxo or a hydroxide ligand, the metal- $\mathrm{O}(5)$ distances returned in such models are quite discrepant from the XRD results. Nor is $\mathrm{O}(5)$ well modeled as discrete water ligand. We infer that $\mathrm{O}(5)$ within the crystal structure is best interpreted as an 'activated water' species, such as $\mathrm{H}_{2} \mathrm{O}$ proton-bound to a neighbouring hydroxide ion. Calculations on such a species are being pursued.

At least three recent DFT studies, addressing among other things, the $1.9 \AA$ XRD structure, have asserted ${ }^{19,31,34}$ that this structure is contaminated by pre- $\mathrm{S}_{0}$-state intermediates such as $\mathrm{S}_{-1}$ and perhaps $\mathrm{S}_{-2}$. This position derives from the consistent assumption by the above authors that the water-oxidising complex adheres to the HOS paradigm, ${ }^{55}$ while Kusunoki ${ }^{33}$ suggests that the $1.9 \AA$ structure represents an equilibrium between two different isomers. We find computationally however that the metal-metal distances can be generally well matched by stand-alone $S_{1}$ structures, somewhat more closely within the LOS than HOS paradigm, if the oxidation state pattern (rather than mean level) is altered from that likely to apply within the photosystem $S_{1}$ state, as frequently prepared for experimental study. There is no necessity to invoke 
Table 6 Comparison of the metal-metal distances of the $1.9 \AA$ resolution XRD with recent results obtained from the models of various groups



excessive Mn reduction and consequent structural perturbation to account for the observed geometry of the WOC in the $1.9 \AA$ XRD structure. Indeed we find such a proposition somewhat surprising, given the high quality and resolution of the $1.9 \AA$ XRD data and the expectation that such radiation induced reduction and damage would be largely a random event. The published results of Umena et al. ${ }^{7}$ report a slight, resolved difference in the photosystem structure near the WOC region and limited other locations, between the two monomers (A and B) within the crystallized PSII dimer. That seems remarkable if the protein has been subject to significant radiation damage during data collection after crystallization.

Thus in contrast to the results of other recent DFT studies addressing the $1.9 \AA$ XRD structure, we find no grounds to argue that this crystal structure is contaminated by $\mathrm{X}$-rayinduced photoreduction of the $\mathrm{Mn}_{4}$ core. The precise relationship between the new 1.9 ̊ XRD structure and those obtained by earlier X-ray crystallographic studies, let alone to functional Photosystem II, remains to be ascertained.

\section{References}

1 A. Zouni, H.-T. Witt, J. Kern, P. Fromme, N. Krauss, W. Saenger and P. Orth, Nature, 2001, 409, 739-743.

2 N. Kamiya and J.-R. Shen, Proc. Natl. Acad. Sci. U. S. A., 2003, 100, 98-103.
3 J. Biesiadka, B. Loll, J. Kern, K.-D. Irrgang and A. Zouni, Phys. Chem. Chem. Phys., 2004, 6, 4733-4736.

4 K. N. Ferreira, T. M. Iverson, K. Maghlaoui, J. Barber and S. Iwata, Science, 2004, 303, 1831-1838.

5 B. Loll, J. Kern, W. Saenger, A. Zouni and J. Biesiadka, Nature, 2005, 438, 1040-1044.

6 A. Guskov, J. Kern, A. Gabdulkhalov, M. Broser, A. Zouni and W. Saenger, Nat. Struct. Mol. Biol., 2009, 16, 334-342.

7 Y. Umena, K. Kawakami, J. R. Shen and N. Kamiya, Nature, 2011, 473, 55-60.

8 S. Petrie, R. Stranger, P. Gatt and R. J. Pace, Chem.-Eur. J., 2007, 13, 5082-5089.

9 S. Petrie, R. Stranger and R. J. Pace, Chem.-Eur. J., 2008, 14 $5482-5494$.

10 J. Yano, J. Kern, K.-D. Irrgang, M. J. Latimer, U. Bergmann, P. Glatzel, Y. Pushkar, J. Biesiadka, B. Loll, K. Sauer, J. Messinger, A. Zouni and V. K. Yachandra, Proc. Natl. Acad. Sci. U. S. A., 2005, 102, 12047-12052.

11 P. Gatt, R. Stranger and R. J. Pace, J. Photochem. Photobiol., B, 2011, 104, 80-93.

12 J. P. McEvoy, J. A. Gascon, V. S. Batista and G. W. Brudvig, Photochem. Photobiol. Sci., 2005, 4, 940-949.

13 E. M. Sproviero, J. A. Gascon, J. P. McEvoy, G. W. Brudvig and V. S. Batista, J. Inorg. Biochem., 2006, 100, 786-800.

14 E. M. Sproviero, J. A. Gascon, J. P. McEvoy, G. W. Brudvig and V. S. Batista, J. Chem. Theory Comput., 2006, 2, 1119-1134.

15 E. M. Sproviero, J. A. Gascon, J. P. McEvoy, G. W. Brudvig and V. S. Batista, J. Am. Chem. Soc., 2008, 130, 3428-3442.

16 E. M. Sproviero, J. A. Gascon, J. P. McEvoy, G. W. Brudvig and V. S. Batista, J. Am. Chem. Soc., 2008, 130, 6728-6730.

17 E. M. Sproviero, J. P. McEvoy, J. A. Gascon, G. W. Brudvig and V. S. Batista, Photosynth. Res., 2008, 97, 91-114. 
18 E. M. Sproviero, M. B. Newcomer, J. A. Gascon, E. R. Batista, G. W. Brudvig and V. S. Batista, Photosynth. Res., 2009, 102, 455-470.

19 S. Luber, I. Rivalta, Y. Umena, K. Kawakami, J.-R. Shen, N. Kamiya, G. W. Brudvig and V. S. Batista, Biochemistry, 2011, 50, 6308-6311.

20 P. E. M. Siegbahn, Q. Rev. Biophys., 2003, 36, 91-145.

21 M. Lundberg and P. E. M. Siegbahn, Phys. Chem. Chem. Phys., 2004, 6, 4772-4780.

22 P. E. M. Siegbahn and M. Lundberg, Photochem. Photobiol. Sci., 2005, 4, 1035-1043.

23 P. E. M. Siegbahn and M. R. A. Blomberg, Philos. Trans. R. Soc., $A, 2005,363,847-860$.

24 P. E. M. Siegbahn and M. Lundberg, J. Inorg. Biochem., 2006, 100, 1035-1040.

25 P. E. M. Siegbahn, Chem.-Eur. J., 2006, 12, 9217-9227.

26 P. E. M. Siegbahn, Philos. Trans. R. Soc., B, 2008, 363, 1221-1228.

27 P. E. M. Siegbahn, Inorg. Chem., 2008, 47, 1779-1786.

28 P. E. M. Siegbahn, Dalton Trans., 2009, 5832-5840.

29 S. Schinzel, J. Schraut, A. V. Arbuznikov, P. E. M. Siegbahn and M. Kaupp, Chem.-Eur. J, 2010, 16, 10424-10438.

30 P. E. M. Siegbahn, J. Photochem. Photobiol., B, 2011, 104, 94-99.

31 P. E. M. Siegbahn, ChemPhysChem, 2011, 12, 3274-3280.

32 M. Kusunoki, Biochim. Biophys. Acta, Bioenerg., 2007, 1767, 484 492; M. Kusunoki, Biochim. Biophys. Acta, Bioenerg., 2008, $1777,477$.

33 M. Kusunoki, J. Photochem. Photobiol., B, 2011, 104, 100-110.

34 W. Ames, D. A. Pantazis, V. Krewald, N. Cox, J. Messinger, W. Lubitz and F. Neese, J. Am. Chem. Soc., 2011, 133, 19743-19757.

35 K. Kanda, S. Yamanaka, T. Saito, Y. Umena, K. Kawakami, J.-R. Shen, N. Kamiya, M. Okumura, H. Nakamura and K. Yamaguchi, Chem. Phys. Lett., 2011, 506, 98-103.

36 T. Saito, S. Yamanaka, K. Kanda, H. Isobe, Y. Takano, Y. Shigeta, Y. Umena, K. Kawakami, J.-R. Shen, N. Kamiya, M. Okumura, M. Shoji, Y. Yoshioka and K. Yamaguchi, Int. J. Quantum Chem., 2012, 112, 253-276.

37 S. Yamanaka, T. Saito, K. Kanda, H. Isobe, Y. Umena, K. Kawakami, J.-R. Shen, N. Kamiya, M. Okumura, H. Nakamura and K. Yamaguchi, Int. J. Quantum Chem., 2012, 112, 321-343.

38 S. Petrie, R. Stranger and R. J. Pace, Angew. Chem., Int. Ed., 2010, 49, 4233-4236.

39 S. Petrie, R. Stranger and R. J. Pace, Chem.-Eur. J., 2010, 16, 14026-14042.

40 S. Petrie, P. Gatt, R. Stranger and R. J. Pace, Phys. Chem. Chem. Phys., 2012, 14, 4651-4657.

41 A. R. Jaszewski, R. J. Pace and R. Stranger, J. Phys. Chem. B, 2011, 115, 4484-4499.

42 A. R. Jaszewski, S. Petrie, R. J. Pace and R. Stranger, Chem.-Eur. J., 2011, 17, 5699-5713.
43 A. R. Jaszewski, R. J. Pace and R. Stranger, J. Phys. Chem. A, 2008, 112, 11223-11234.

44 A. R. Jaszewski, R. J. Pace and R. Stranger, Phys. Chem. Chem. Phys., 2009, 11, 5634-5642.

45 J. Yano, Y. Pushkar, P. Glatzel, A. Lewis, K. Sauer, J. Messinger, U. Bergmann and V. Yachandra, J. Am. Chem. Soc., 2005, 127, 14974.

46 H. Dau, A. Grundmeier, P. Loja and M. Haumann, Philos. Trans. R. Soc., B, 2008, 363, 1237-1243.

47 E. J. Baerends, J. Autsbach, A. Bérces, F. M. Bickelhaupt, C. Bo, P. M. Boerrigter, L. Cavallo, D. P. Chong, L. Deng, R. M. Dickson, D. E. Ellis, M. v. Faassen, L. Fan, T. H. Fischer, C. Fonseca Guerra, S. J. A. van Gisbergen, J. A. Groeneveld, O. V. Gritsenko, M. Gruning, F. E. Harris, P. van den Hoek, C. R. Jacob, H. Jacobsen, L. Jensen, G. van Kessel, F. Kootstra, E. van Lenthe, D. A. McCormack, A. Michalak, J. Neugebauer, V. P. Osinga, S. Patchkovskii, P. H. T. Philipsen, D. Post, C. Pye, W. Ravenek, P. Ros, P. R. T. Schipper, G. Schreckenbach, J. G. Snijders, M. Sola, M. Swart, D. Swerhone, G. te Velde, P. Vernooijs, L. Versluis, O. Visser, F. Wang, T. A. Wesolowski, E. van Wezenbeek, G. Wiesenekker, S. K. Wolff, T. K. Woo, A. L. Yakovlev and T. Ziegler, Amsterdam Density Functional v.2009.01, S.C.M., Theoretical Chemistry, Vrije Universiteit, Amsterdam, The Netherlands, http://www.scm.com. 48 L. Versluis and T. Ziegler, J. Chem. Phys., 1988, 88, 322-328.

49 S. H. Vosko, L. Wilk and M. Nusair, Can. J. Phys., 1980, 58, 1200. 50 A. D. Becke, Phys. Rev. A, 1988, 38, 3098-3100.

51 J. P. Perdew, Phys. Rev. B: Condens. Matter Mater. Phys., 1986, 33, 8822

52 T. Schwabe and S. J. Grimme, Phys. Chem. Chem. Phys., 2007, 9, $3397-3406$.

53 It should be noted, however, that the 'truncated' models employed in this set of calculations do not address the possibility that $\mathrm{O}(2)$ is hydrogen-bonded to the adjacent His 337 residue through a shared proton. Such H-bonding would be expected to yield $\mathrm{Mn}(1)-\mathrm{Mn}(2)$ and $\mathrm{Mn}(2)-\mathrm{Mn}(3)$ distances intermediate between those seen for unprotonated and protonated $\mathrm{O}(5)$ in these 'truncated' models ${ }^{40}$.

54 The study of Ames et al. ${ }^{34}$ also centres on interpretation of the $1.9 \AA$ XRD geometry, but takes as its reference geometry a significantly 'corrected' version of the $1.9 \AA$ structure with substantially shorter $\mathrm{Mn}(2)-\mathrm{Mn}(3), \mathrm{Mn}(3)-\mathrm{Mn}(4)$, and $\mathrm{Mn}(1)-\mathrm{Mn}(4)$ distances than are directly determined in the $1.9 \AA$ XRD. We have accordingly not incorporated the results of Ames et al. ${ }^{34}$ (which do not closely match the $1.9 \AA$ geometry) in our comparison in Table 6.

55 In fact, Grundmeier and $\mathrm{Dau}^{56}$ have asserted that the $\mathrm{Mn}-\mathrm{Mn}$ distances of the $1.9 \AA$ structure are best explained by invoking an oxidation state pattern of $\left(\mathrm{Mn}^{\mathrm{II}}\right)_{2}\left(\mathrm{Mn}^{\mathrm{III}}\right)_{2}$, which would correspond to $\mathrm{S}_{-3}$ in the HOS paradigm and $\mathrm{S}_{-1}$ in the LOS model.

56 A. Grundmeier and H. Dau, Biochim. Biophys. Acta, 2011, 1817, 88-105.

57 R. J. Pace, R. Stranger and S. Petrie, Dalton Trans., 2012, 7179-7189. 